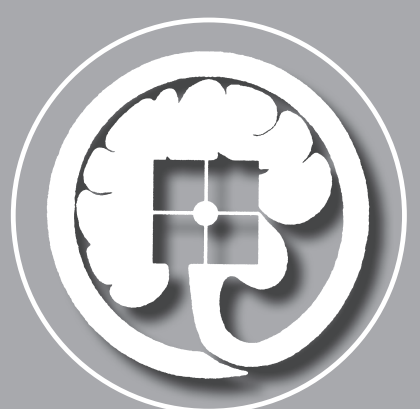

\section{Executive Council}

\section{President}

Ali R. Rezai, MD

Department of Neurosurgery

Center for Neuromodulation

The Ohio State University

$\mathrm{N}-1043$ Doan Hall

410 W. 10th Avenue

Columbus, $\mathrm{OH} 43210$

Tel. (614) 3662420

Fax: (614) 293-4024

ali.rezai@osumc.edu

\section{Vice-President}

Konstantin V. Slavin, MD

Department of Neurosurgery

University of Illinois at Chicago

912 S. Wood St., M/C 799

Chicago, IL 60612

Tel. (312) 9964842

Fax: (312) 9969018

kslavin@uic.edu

\section{Secretary and Treasurer}

Aviva Abosch, MD, PhD

Department of Neurosurgery

University of Minnesota Medical School

D429 Mayo Memorial Building

420 Delaware Street S.E.

MMC 96

Minneapolis, MN 55455

Tel. (612) 6268786

Fax: (612) 6240644

aabosch@umn.edu

\section{Past-President}

Philip A. Starr, MD, PhD

UCSF Department of Neurosurgery

505 Parnassus Ave., 779 Moffitt

San Francisco, CA 94143

Tel. (415) 3533489

Fax: (415) 5024276

starrp@neurosurg.ucsf.edu

\section{Board Members}

Emad N. Eskandar, MD (2008-2012)

Christopher R. Honey, MD (2008-2012)

Brian H. Kopell, MD (2008-2012)

Alon Y. Mogilner, MD, PhD (2008-2012)

Robert E. Gross, MD, PhD (2010-2014)

Clement Hamani, MD, PhD (2010-2014) Michael G. Kaplitt, MD, PhD (2010-2014)

Peter E. Konrad, MD, PhD (2010-2014) Kendall H. Lee, MD, PhD (2010-2014)

Ashwini D. Sharan, MD (2010-2014)

\section{Society Administrator}

Melody Dian

Tel. 715-327-8818

website: www.assfn.org

\section{American Society for Stereotactic and Functional Neurosurgery}

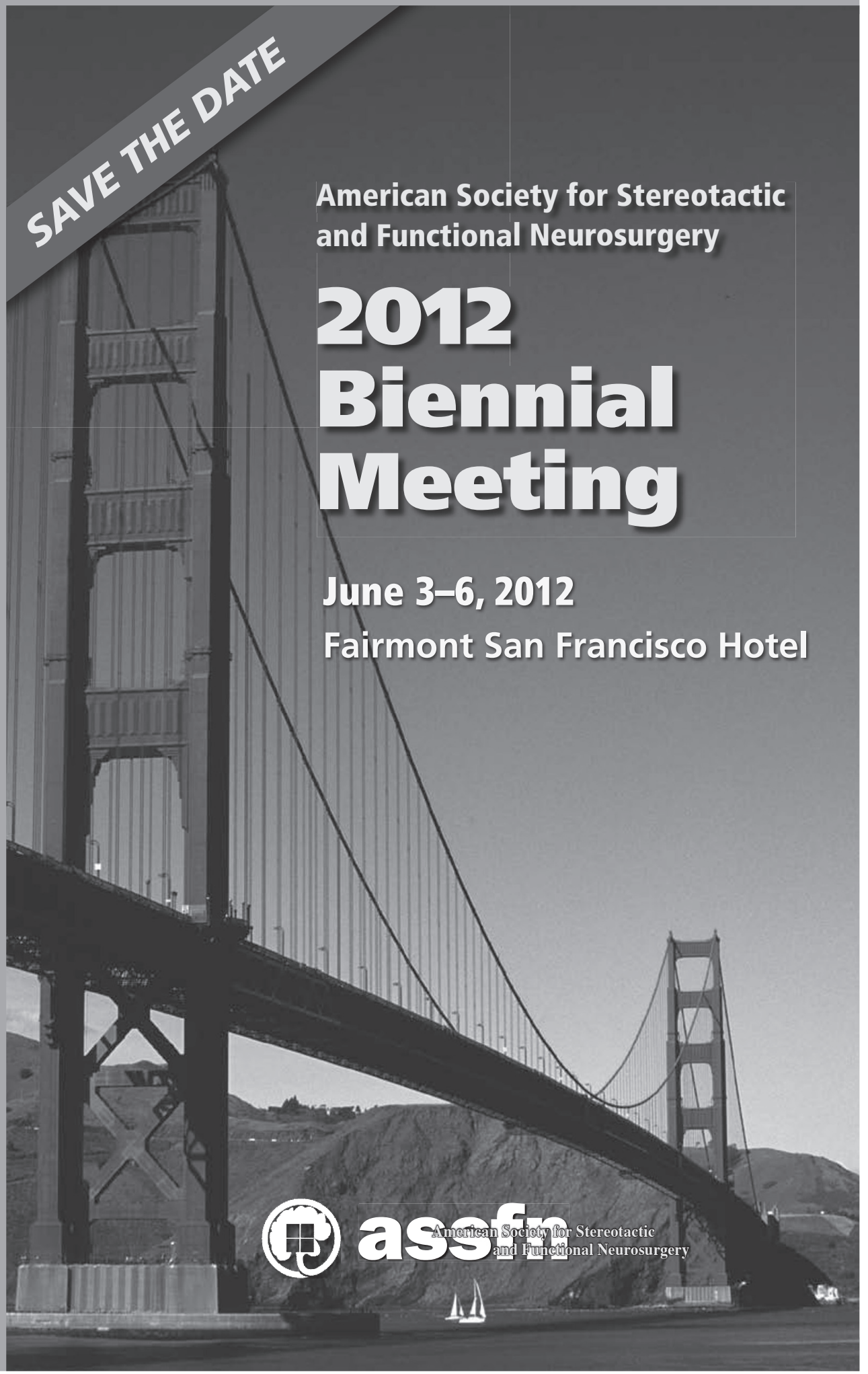

